\title{
Chemical characterization of humic substances occurring in the peats of Sarawak, Malaysia
}

\author{
Sim Siong Fong *, Murtedza Mohamed \\ Faculty of Resource Science and Technology, Universiti Malaysia Sarawak, 94300 Kota Samarahan, Sarawak, Malaysia
}

Received 25 May 2006; received in revised form 2 November 2006; accepted 14 December 2006

Available online 11 January 2007

\begin{abstract}
The chemical characteristics of humic substances (HS) extracted from several samples of peat soils of Sarawak, Malaysia, were determined by size exclusion chromatography, FTIR, UV-Vis, acid-base titration, and elemental and total hydrolysable carbohydrate analyses. The results showed that the total acidity of these HS ranged between 5.8 and $8.3 \mathrm{meq} / \mathrm{g}$, with a clear indication that the fulvic acid component contained more carboxylic groups compared to humic acids. A comparison with the literature data for HS occurring elsewhere showed that the tropical peat of Sarawak has higher carboxylic and phenolic contents, is richer in carbohydrate moiety and also is more oxygenated. The UV-Vis analyses gave a relatively high $E_{4} / E_{6}$ ratio, implying the prominence of aliphatic components. The relatively lower range of $M_{\mathrm{w}}$ further suggested the dominance of smaller-sized humic molecules. These structural attributes suggest that the local HS may exhibit a strong complexing capability and greater susceptibility to electrophilic cleavage by trihalomethane-forming agents.
\end{abstract}

(c) 2007 Elsevier Ltd. All rights reserved.

\section{Introduction}

Peatlands worldwide are recognized to play a vital role in biosphere biogeochemical processes. Lowland tropical peatland, for instance, links forest to freshwater ecosystems, and forms an outstanding carbon store. Thus, peat soils contain significant quantities (at least $30 \%$ ) of organic matter, some of which are complex aromatic macromolecules collectively known as humic substances (HS).

Studies have suggested that HS might be dynamically involved in carbon and electron flow in anaero-

\footnotetext{
* Corresponding author. Tel.: +60 82670483; fax: +60 82672275.

E-mail address: sfsim@frst.unimas.my (S.S. Fong).
}

bic environments, which implies their potential role in pollutant transformation (Lovely et al., 1996). On the other hand, HS have been linked to unfavorable impacts on water treatment processes. They contribute to odor, color, taste as well as acidity problems in water supplies. They increase the demand of coagulants, resulting in elevated residual aluminium in treated water, and they compete with other pollutants for adsorption sites on activated carbon. Furthermore, they have been identified as one of the major precursors for trihalomethane formation during water disinfection (chlorination) processes (Vik and Eikebrokk, 1989). It is therefore crucial that the chemical characteristics of HS be well understood as this would lead to better insights into the underlying mechanisms responsible for the complexation, 
reduction, bioavailability, mobilization or immobilization of metals and toxic organic chemicals.

Extensive studies have been carried out elsewhere to characterize HS, but these were almost exclusively of those found in temperate regions. There are major differences between the genesis, evolution and vegetation cover of the peatlands of boreal/temperate and of tropical zones. In the tropics, lowland peat-forming systems are almost exclusively subcoastal in location and influenced by a climate that is hot and humid with little temperature variation. Initiation of tropical peat is unlikely to have conformed to the open water/fen model favored for boreal/temperate peatlands and probably commenced in response to substrate waterlogging caused by extremely high rainfall and permanent flooding (Sieffermann et al., 1988).

Thus, the information derived for temperate HS might not be entirely applicable to those of the humid tropics. The size, chemical composition and functional group characteristics of HS may vary greatly, depending on the origin and age of the material (Chin et al., 1998). This paper describes a preliminary study to determine the key chemical features of humic and fulvic acid components of HS obtained from the tropical peat soil, soil interstitial water and peat swamp runoff (stream water) of Sarawak, Malaysia.

\section{Materials and methods}

\subsection{Sampling sites}

Grab samples of peat soil, soil interstitial water and stream water from six localities in Sarawak (Fig. 1) were collected and stored at $4{ }^{\circ} \mathrm{C}$ for isolation of HS. The soil and soil interstitial samples were collected from Kota Samarahan. The water samples were collected from various rivers situated in Kuching (Karat River), Lundu (Stunggang River), Kota Samarahan (Asa Jaya River), Sibu (Merah River) and Miri (Miri River and Bakong River). The samples were subjected to extraction and analyses with HPLC, FTIR, UV-Vis, as well as acid-base content determination. Representative soil and water samples from Kota Samarahan were chosen for elemental composition and carbohydrate

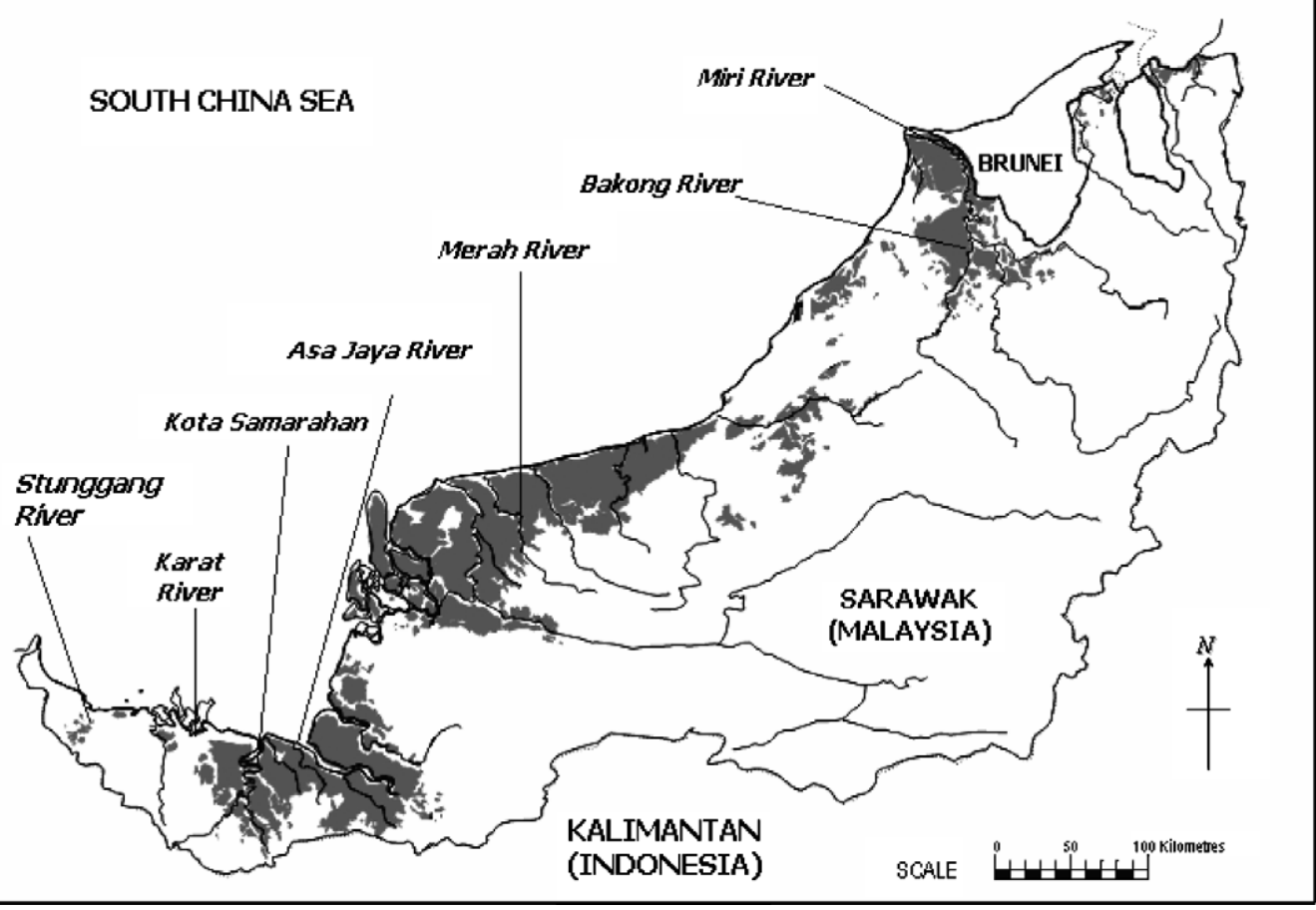

Fig. 1. Sampling sites (arrowed) and distribution of peat soils (shaded) in Sarawak. 